\title{
Dopaminergic Neurons Intrinsic to the Primate Striatum
}

\author{
Ranjita Betarbet, ${ }^{1}$ Robert Turner. ${ }^{1}$ Vijay Chockkan, ${ }^{1}$ Mahlon R. DeLong, ${ }^{1}$ Kelly A. Allers, ${ }^{2}$ Judith Walters, ${ }^{3}$ \\ Allan I. Levey, ${ }^{1}$, and J. Timothy Greenamyre ${ }^{1,4,5}$ \\ ${ }^{1}$ Department of Neurology, ${ }^{2}$ Graduate Program in Neuroscience, ${ }^{4}$ Department of Pharmacology, and the 5 Yerkes Regional \\ Primate Research Center, Emory University, Atlanta, Georgia 30322, and the ${ }^{3}$ Laboratory of the National Institute of \\ Neurological Disorders and Stroke, Bethesda, Maryland 20892-1406
}

Intrinsic, striatal tyrosine hydroxylase-immunoreactive ( $\mathrm{TH}-\mathrm{i})$ cells have received little consideration. In this study we have characterized these neurons and their regulatory response to nigrostriatal dopaminergic deafferentation. $\mathrm{TH}$-i cells were observed in the striatum of both control and 1-methyl-4-phenyl1,2,3,6-tetrahydropyridine (MPTP)-treated monkeys; TH-i cell counts, however, were 3.5-fold higher in the striatum of MPTPlesioned monkeys. To establish the dopaminergic nature of the $\mathrm{TH}-\mathrm{i}$ cells, sections were double-labeled with antibodies to dopamine transporter (DAT). Immunofluorescence studies demonstrated that nearly all $\mathrm{TH}-\mathrm{i}$ cells were double-labeled with DAT, suggesting that they contain the machinery to be functional dopaminergic neurons. Two types of $\mathrm{TH}$-i cells were identified in the striatum: small, aspiny, bipolar cells with varicose dendrites and larger spiny, multipolar cells. The aspiny cells, which were more prevalent, corresponded morphologically to the GABAergic interneurons of the striatum. Double-

The clinical features of Parkinson's disease result from degeneration of the nigrostriatal pathway and striatal dopamine deficiency (Ehringer and Hornykiewicz, 1960). The striatum, which is composed of caudate, putamen, and nucleus accumbens, is the major input nucleus of the basal ganglia. It is the target of inputs from the entire cortex and certain thalamic nuclei (parafascicular and centromedian nucleus) and provides output to other nuclei of the basal ganglia. The striatum is composed primarily of spiny projection neurons (DiFiglia et al., 1976; Bishop et al., 1982; Gerfen and Wilson, 1996), which constitute $\sim 95 \%$ of the striatal neuronal population (Kemp and Powell, 1971). These projection neurons are also the major target of afferents to the striatum. Morphological characteristics of these neurons include a cell body ranging from 10 to $20 \mu \mathrm{m}$ in diameter, with four to seven primary dendrites arising from the soma and secondary and tertiary branches covered with spines. Projection neurons use GABA as a neurotransmitter (Parent et al., 1995) and contain glutamic acid decarboxylase (GAD), the synthetic enzyme for GABA (Kita and Kitai, 1988). Furthermore, retrograde tracer experiments have revealed that the majority of striatal calbindin-immunoreactive neurons are the source of striatonigral projections (Gerfen et al., 1985).

Received April 21, 1997; revised June 4, 1997; accepted June 11, 1997.

This work was supported by United States Public Health Service Grants NS33779 (J.T.G.) and NS31937 (A.I.L. and M.R.D.) and a Mallinckrodt Scholar Award (J.T.G.). We thank Dr. Stacy Stephans for her comments on this manuscript.

Correspondence should be addressed to Dr. J. Timothy Greenamyre, Department of Neurology, Emory University, 1639 Pierce Drive, WMB 6000, Atlanta, GA 30322.

Copyright (C) 1997 Society for Neuroscience $0270-6474 / 97 / 176761-08 \$ 05.00 / 0$ label immunofluorescence studies using antibodies to $\mathrm{TH}$ and glutamate decarboxylase $\left(\mathrm{GAD}_{67}\right)$, the synthetic enzyme for GABA, showed that $99 \%$ of the $\mathrm{TH}$-i cells were $\mathrm{GAD}_{67}$-positive. Very few $(<1 \%)$ of the $\mathrm{TH}-\mathrm{i}$ cells, however, were immunoreactive for the calcium-binding proteins calbindin and parvalbumin. In summary, these results demonstrate that the dopaminergic cell population of the striatum responds to dopamine denervation by increasing in number, apparently to compensate for loss of extrinsic dopaminergic innervation. Moreover, this population of cells corresponds largely with the intrinsic GABAergic cells of the striatum. This study also suggests that the adult primate striatum does retain some intrinsic capacity to compensate for dopaminergic cell loss.

Key words: striatum; dopaminergic cells; Parkinson's disease-treated monkeys; dopamine transporter; glutamic acid decarboxylase; calbindin; parvalbumin

The remaining striatal neurons are interneurons (DiFiglia et al., 1976; Bishop et al., 1982) that have been classified into a variety of morphological and neurochemical subtypes. One subtype consists of large, aspiny, cholinergic neurons with cell body diameters ranging from 25 to $40 \mu \mathrm{m}$ (Bolam et al., 1984). The other subtype includes the medium, aspiny neurons that can be further subdivided into two types. One uses GABA as a transmitter (Bolam et al., 1983; Oertel and Mugnaini, 1984; Smith et al., 1987; Pasik et al., 1988; Kita, 1993), is specifically stained with antibodies to parvalbumin (Gerfen et al., 1985; Cowan et al., 1990; Kita et al., 1990), and has a round or oval-shaped cell body, 8-15 $\mu \mathrm{m}$ in diameter, with two or three varicose dendrites extending from the soma (DiFiglia et al., 1976; Bishop et al., 1982). The other type of medium, aspiny interneuron is characterized by a fusiform cell body that stains for somatostatin, neuropeptide Y, or nitric oxide synthase (Vincent et al., 1983a,b; Smith and Parent, 1986; Dawson et al., 1991). These differ from GABAergic interneurons in that they have fusiform cell bodies and fewer dendritic branches (Gerfen and Wilson, 1996). In contrast to the well-characterized interneuron subtypes, another group of cells immunoreactive for tyrosine hydroxylase ( $\mathrm{TH}-\mathrm{i})$ exists in the striatum, which have been described by Dubach et al. (1987) in nonhuman primates and by Tashiro et al. (1989) in rats. Apart from these initial descriptions, little consideration has been given to TH-i striatal cells in the adult striatum.

We have investigated the morphological characteristics, cotransmitter status, and catecholaminergic nature of TH-expressing cells in the striatum of adult rats and nonhuman primates. The 
effects of dopamine denervation on TH expression by adult striatal cells were also determined. Dopaminergic cells of the substantia nigra were selectively destroyed by treating rats with 6-hydroxydopamine (6-OHDA) (Ungerstedt, 1968, 1971) and rhesus monkeys with 1-methyl-4-phenyl-1,2,3,6-tetrahydropyridine (MPTP) (Burns et al., 1983; Langston et al., 1983; Heikkila et al., 1984). Our results suggest the adult striatum retains the ability to compensate, in part, for dopamine depletion.

\section{MATERIALS AND METHODS}

Animals. All animal use was in accordance with National Institutes of Health guidelines and was approved by the Emory University Institutional Animal Care and Use Committee. In this study, brains of seven adult rhesus monkeys, ranging in age from 7 to 14 years, and six adult Sprague Dawley rats were examined. Of the seven monkeys, three unlesioned monkeys were used as controls, two monkeys received unilateral infusions of MPTP $(0.4 \mathrm{mg} / \mathrm{kg})$ into the internal carotid artery to produce a stable contralateral parkinsonian syndrome, and the remaining two monkeys were rendered bilaterally parkinsonian by intramuscular injections of MPTP $(0.5 \mathrm{mg} / \mathrm{kg}$ every $2-5 \mathrm{~d})$ over $2-6$ weeks. The two monkeys with intramuscular MPTP injections were part of a separate study, not reported here, wherein lesion of the right subthalamic nucleus was attempted unsuccessfully. Six rats with unilateral 6-OHDA lesions of the nigrostriatal pathway were obtained from Zivic Miller. The monkeys with unilateral lesions were killed about 2 years after receiving MPTP; those with bilateral parkinsonism were killed within 2 months of their last MPTP treatment. Rats were killed about 1 month after lesioning. None of the monkeys received more than two or three treatments with a dopaminergic drug, and none of the animals received any pharmacological treatment within 4 weeks of killing. After ketamine sedation, the monkeys were given an intravenous overdose of sodium pentobarbital, whereas the rats received an overdose of equithesin. The animals were intracardially perfused with 3 or $4 \%$ paraformaldehyde in $0.1 \mathrm{M}$ phosphate buffer (PB), $\mathrm{pH}$ 7.2. The brains were removed and cryoprotected in a $30 \%$ sucrose solution in $0.1 \mathrm{M} P B$.

Immunocytochemistry. Fifty micrometer ( $40 \mu \mathrm{m}$ for rats) coronal sections, cut on a freezing microtome, were collected in $0.1 \mathrm{M}$ PB containing $30 \%$ sucrose and $30 \%$ ethylene glycol and stored at $-70^{\circ} \mathrm{C}$. Sections through the striatum were thoroughly washed in $0.1 \mathrm{M} \mathrm{PB}$ to remove the cryoprotectant and incubated in $10 \%$ normal goat serum with $0.04 \%$ Triton X-100 in PB for 30 min. They were then incubated for $72 \mathrm{hr}$ in the same solution containing either primary antibody to TH (1:500, rabbit polyclonal antibody, Pel-Freeze Biologicals; 1:1000, rabbit polyclonal antibody, Eugene Tech; 1:2000, mouse monoclonal antibody, Chemicon) or a mixture of primary antibodies, which would include antibodies to TH and antibodies to microtubule-associated protein 2 (MAP2; 1:500, a mouse monoclonal antibody; Sigma, St. Louis, MO), the dopamine transporter (DAT; 1:125, rat monoclonal antibody) (Miller et al., 1997), $\mathrm{GAD}_{67}(1: 2000$, rabbit polyclonal antibody; Chemicon), calbindin (CaBP; 1:200, mouse monoclonal antibody; Sigma), parvalbumin (PV; 1:500, mouse monoclonal antibody; Sigma), or neuronal nitric oxide synthase (nNOS; $2 \mu \mathrm{g} / \mathrm{ml}$, rabbit polyclonal antibody; Upstate Biotechnology, Lake Placid, NY). Then the sections were rinsed in $0.1 \mathrm{M} \mathrm{PB}$ and incubated for $2 \mathrm{hr}$ in a combination of secondary antibodies. For immunofluorescence staining, TH was visualized using either fluorescein isothiocyanate (FITC) conjugated to goat anti-mouse or goat anti-rabbit IgG (1:200; Jackson ImmunoResearch, West Grove, PA); DAT was visualized using Texas Red conjugated to goat anti-rat IgG (1:200; Jackson ImmunoResearch); $\mathrm{GAD}_{67}$ and nNOS were visualized using Texas Red conjugated to goat anti-rabbit IgG; and MAP2, CaBP, and PV were visualized using Texas Red conjugated to goat anti-mouse IgG. Finally, the sections were rinsed in $0.1 \mathrm{M} \mathrm{PB}$, mounted on gelatin-coated slides, and coverslipped using Vectashield (Vector Laboratories, Burlingame, CA). For enzyme-linked staining of TH-positive cells, the ABC biotin-avidin complex method was used, and 3,3'-diaminobenzidine tetrachloride was used to visualize the final product. For control sections, one or both of the primary antibodies were omitted.

The enzyme-linked immunostained sections were examined using a bright-field microscope (Olympus BH-2). The immunofluorescencestained sections were visualized using conventional fluorescence and confocal microscopy. Images were collected on a Leitz fluorescence microscope linked to an MCID image analysis system (Imaging Research, St. Catharines, Ontario, Canada) with selective filter sets to

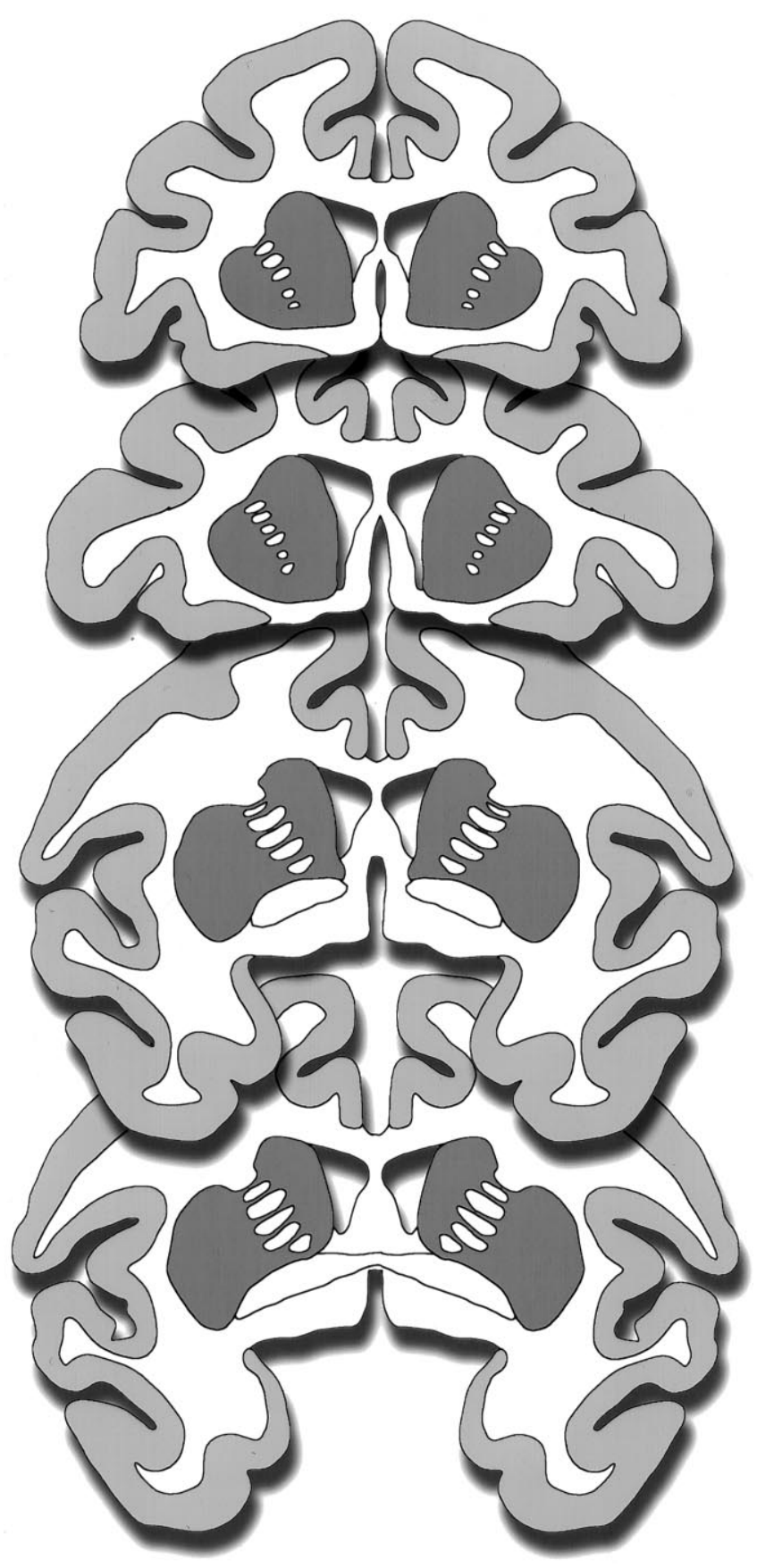

Figure 1. Schematic diagrams of representative coronal sections through a monkey brain illustrating the striatal areas (dark gray areas) analyzed for TH-i cell counts. Two sections at different levels anterior to and two sections at the level of the anterior commissure were analyzed from each animal.

visualize FITC or Texas Red separately as well as simultaneously. Confocal images were collected using a Meridian InSight point laser confocal system equipped with a Zeiss Axioplan microscope and argon and krypton lasers. The argon laser with a wavelength of $488 \mathrm{~nm}$ was used to excite FITC, and the krypton laser with a wavelength of $568 \mathrm{~nm}$ was used to excite Texas Red. For selective visualization of FITC and Texas Red, the 530/30 bandpass and the 605 long-pass filters were used, respectively. The confocal pinhole aperture setting varied from 40 to 113 $\mu \mathrm{m}$ depending on the chromophore used. Images were visualized using a Zeiss Plan-Neofluar $100 \times$ oil-immersion objective with a numerical aperture of 1.4. Control experiments with single-labeled sections confirmed that there was no "bleed" of fluorescence from FITC through the 

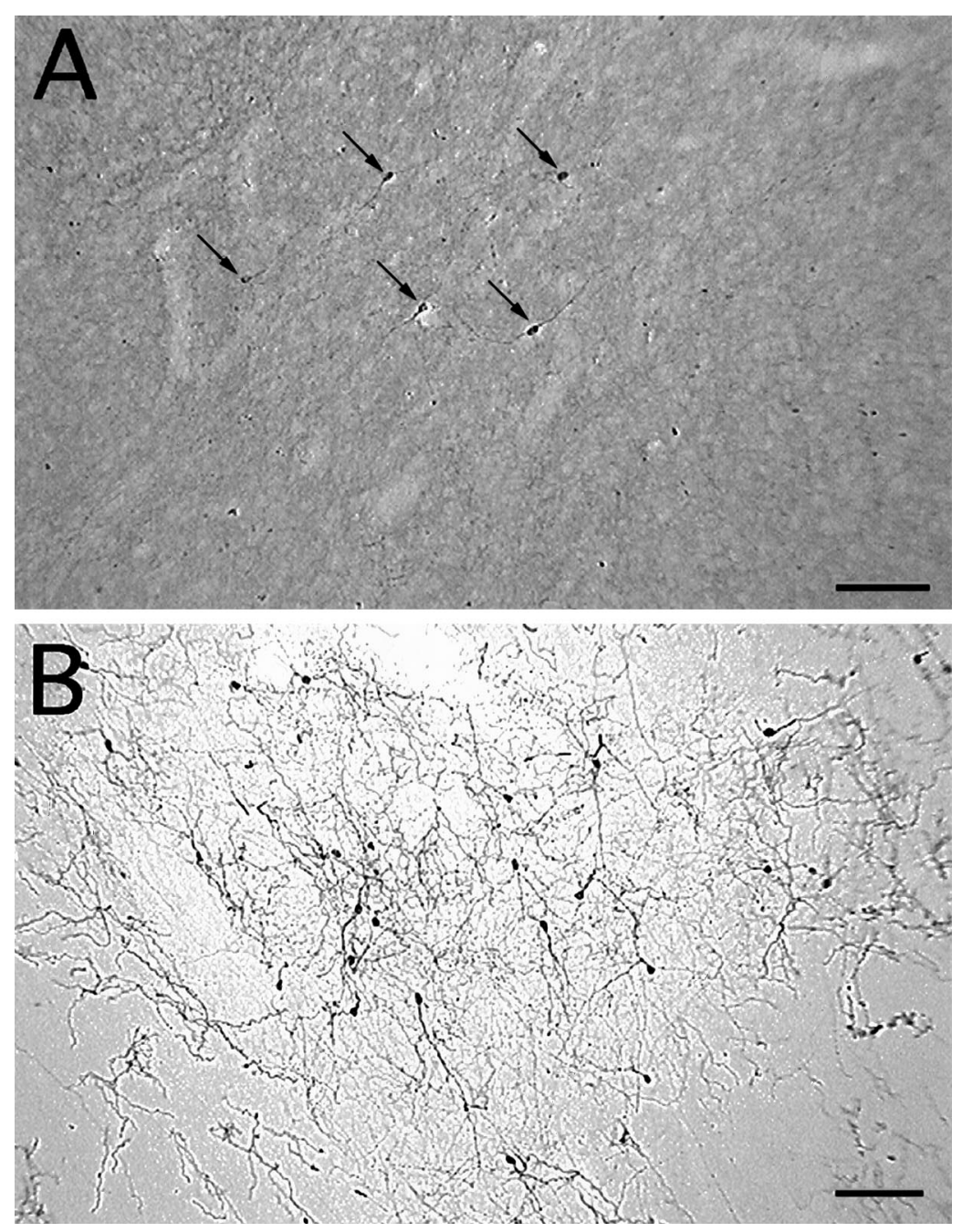

Figure 2. TH-i cells in the striatum of a control monkey $(A)$ and an MPTP-treated monkey $(B)$. Note the increase in TH-i cell density in the dopamine-depleted striatum $(B)$. Because of the presence of intact nigrostriatal dopaminergic fibers, the neuropil in the control striatum $(A)$ is more intensely stained than in the dopamine-denervated striatum $(B)$. Nevertheless, TH-i cells are easily discerned in control tissue $(A)$. All the TH-i cells in this field are indicated by arrows $(A)$. Scale bar, $100 \mu \mathrm{m}$.
Texas Red filters or from Texas Red fluorescence through the FITC filters. Three-dimensional reconstructions of TH-i cells were made by obtaining a $z$ series of optical sections at $0.5 \mu \mathrm{m}$ steps throughout the section thickness and using the Meridian InSight IQ reconstruction software. For final output, images were processed using Adobe Photoshop.

Quantitation. Because of limited tissue availability, formal stereological techniques could not be used. Instead, all profiles of TH-i neurons (defined as a cell body with one or more processes) in the right and left caudate and putamen were counted from four anatomically matched sections from each of the animals. The sections used for profile counts were all simultaneously processed for immunocytochemistry and stained with the DAB reaction. The profile counts were made using a $20 \times$ objective. The four sections from each animal consisted of two sections at different levels anterior to and two sections at different levels of the anterior commissure (Fig. 1). The counts were compared using an unpaired $t$ test.

\section{RESULTS}

\section{TH-i cells in the striatum of nonhuman primates}

In normal monkeys, $\mathrm{TH}-\mathrm{i}$ cells were found more frequently in certain portions of the striatum. Dorsally, the cells were concentrated toward the dorsal border of the striatum near the corpus callosum. Ventrally, the striatal distribution of TH-i cells appeared to be continuous with dopaminergic cell populations in the ventrobasal regions of the forebrain. Along the lateral edge of the putamen, the cells were present in the neuropil as well as in the adjacent white matter. A few cells also were present within the anterior limb of the internal capsule where it separates the caudate from the putamen. The TH-i cells were typically round or oval, measuring $\sim 6-12 \mu \mathrm{m}$ in diameter (see Fig. $2 A, 4 A, 5$ ). Compared with the $\mathrm{TH}-\mathrm{i}$ cells of the substantia nigra, which are $\sim 25 \mu \mathrm{m}$ in diameter (not shown), the striatal cells were smaller, with a few short, aspiny neuritic processes. The number of cells varied from monkey to monkey with an average of 66 cells in each section. Equivalent staining patterns were obtained in control and MPTP-lesioned monkeys regardless of which of the three anti-TH antibodies (PelFreez, Eugene Tech, or Chemicon) was used.

In the MPTP-treated monkeys, the general distribution of the $\mathrm{TH}-\mathrm{i}$ cells within the striatum was the same as in the normal monkeys. However, the intensity of $\mathrm{TH}$ immunoreactivity and the number of TH-i cells were significantly greater in the MPTPtreated monkeys (Fig. $2 B$ ), especially in the dorsal portions of the caudate and ventrolateral portions of the putamen. In the two monkeys with unilateral MPTP lesions, there was no difference in the number of TH-i cells in the denervated and control striatum; both were increased relative to controls. In other words, unilateral dopamine depletion was associated with a bilateral increase in TH-i neurons. In the control monkeys $(n=3)$, the average cell count was $265 \pm 61$ per four sections, whereas in MPTP-treated monkeys (pooled unilateral and bilateral; $n=4)$ the mean was $950 \pm 200$ per four sections, a $\sim 3.5$-fold increase ( $p<0.05$; Fig. 3 ).

Two distinct subtypes of TH-i striatal cells were identified; 


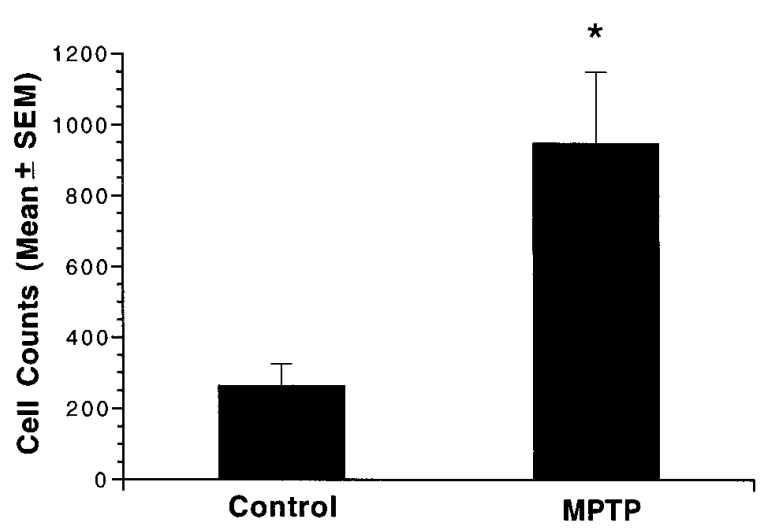

Figure 3. TH-immunoreactive cell counts in the striatum of control and MPTP-treated monkeys. Bars represent the mean \pm SE total cell counts from four anatomically matched sections of striatum from each of three control and four MPTP-treated monkeys. Cell counts in MPTP-treated monkeys were 3.5 -fold greater than in control monkeys $\left({ }^{*} p<0.05\right)$.

aspiny bipolar cells and spiny multipolar cells. More than $99 \%$ of the TH-i cells were of the aspiny, bipolar type, with cell bodies measuring 6-12 $\mu \mathrm{m}$ (Figs. 4A, 5). Some of these neurons had varicose dendrites (Fig. 4), but most of the neurons had smooth, aspiny dendrites (Figs. 4A, 5). The neuritic processes of $\mathrm{TH}-\mathrm{i}$ cells tended to be longer in the striatum of MPTP-treated monkeys, with dendrites extending 200-500 $\mu \mathrm{m}$. A few multipolar $\mathrm{TH}-\mathrm{i}$ cells (one to three per section; $<1 \%$ ) with numerous spines on the dendrites (Fig. 4B) were also identified in the striatum of MPTP-treated monkeys. These cells were larger $(15-20 \mu \mathrm{m})$ than the aspiny bipolar cells.

The striatal TH-i cells uniformly co-expressed MAP2, a neuronal cell marker. All the TH-i cells and fibers in the striatum also double-labeled with antibodies to the dopamine transporter; a representative double-labeled cell is shown in Figure 6. With few exceptions, the TH-i cells $(\sim 99 \%)$ were immunoreactive for $\mathrm{GAD}_{67}$ (see Fig. 7). Very few TH-i cells (about 1\%) were doublelabeled for CaBP (see Fig. 8) or PV (see Fig. 9). None of the TH-i cells stained with antibodies against nNOS. Although most of the neurons in the monkey brains contained some lipofuscin, a pigment associated with aging, the TH-i striatal cells were always devoid of these granules.

\section{TH-i cells in the striatum of rats}

In rat brain, we were unable to identify any $\mathrm{TH}$-i cells in the intact striatum, contralateral to the 6-OHDA lesions. However, in the dopamine-depleted striatum, a few faintly stained $\mathrm{TH}-\mathrm{i}$ cells with one or two short, spidery processes were located in the posterior parts of the ventral striatum (not shown). No TH-i neurons were detected in the more rostral and dorsal portions of striatum associated with motor functions.

\section{DISCUSSION}

The presence of intrinsic TH-positive cells in the striatum is not widely recognized despite two previous reports (Dubach et al., 1987; Tashiro et al., 1989). The reason why these neurons have not been studied in detail may be related to the widespread belief that dopaminergic innervation of the striatum is exclusively extrinsic. Using three different $\mathrm{TH}$ antibodies, we not only confirmed the presence of intrinsic TH-i neurons in the striatum of adult rhesus monkeys, as reported by Dubach et al. (1987), but also found upregulation of TH-i striatal cells in MPTP-lesioned monkeys. Using the same antibodies, we were unable to detect

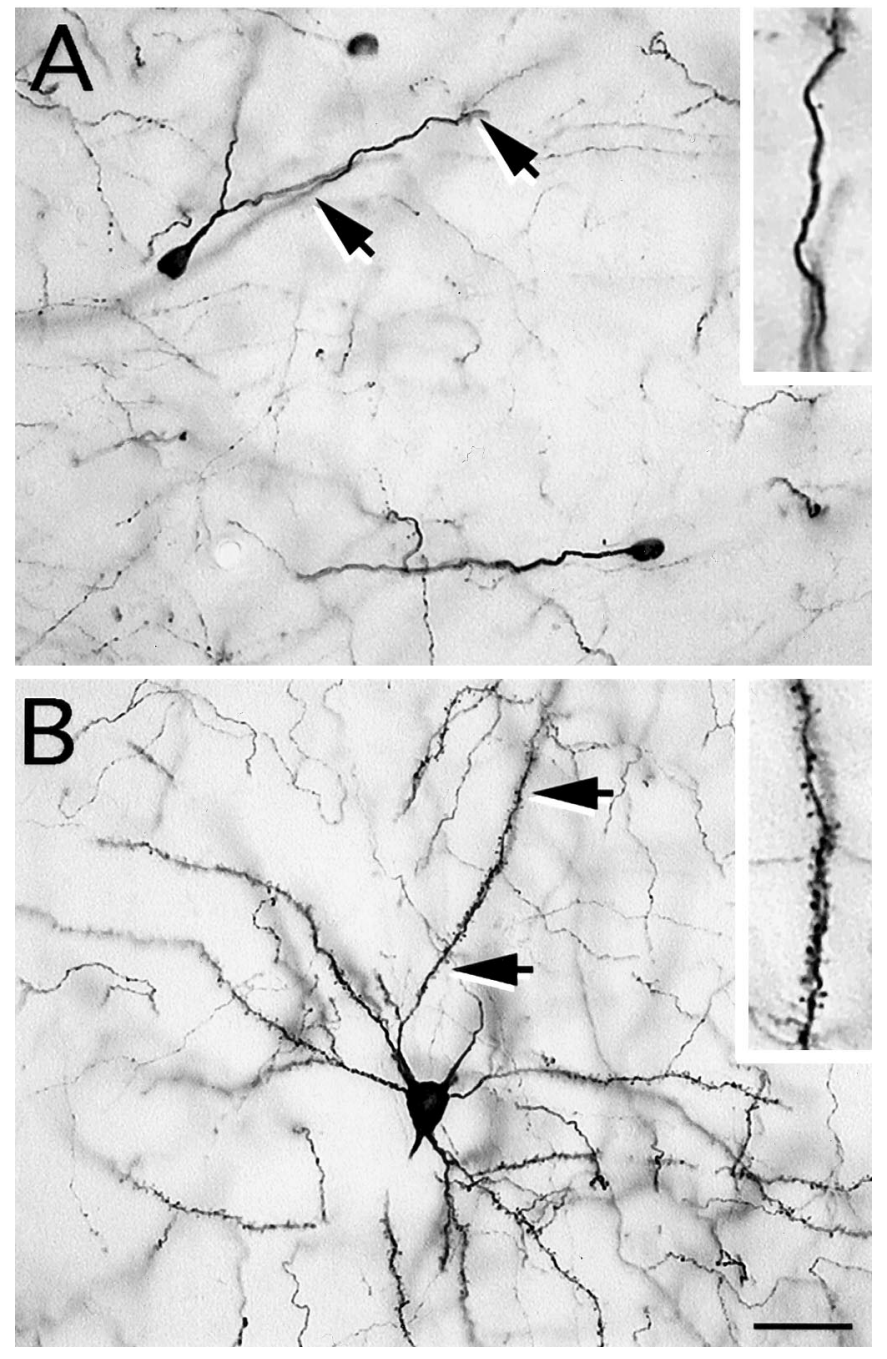

Figure 4. Both aspiny and spiny TH-i neurons were identified in the striatum of MPTP-treated monkeys. $A$, Photomicrograph of an aspiny, oval-shaped neuron with smooth dendrites. These TH-i neurons were observed much more frequently than the spiny neurons after MPTP treatment. $B$, Photomicrograph of a spiny TH-i neuron with a number of primary dendrites that are densely covered with spines. The insets in $A$ and $B$ show a magnified image of a portion of the dendrite denoted by the arrows. Scale bar, $30 \mu \mathrm{m}$.

$\mathrm{TH}-\mathrm{i}$ neurons in rat striatum, except for a few cells in the posterior ventral striatum of 6-OHDA lesioned rats.

\section{Phenotype of TH-i cells in the striatum of MPTP-lesioned monkeys}

Tyrosine hydroxylase catalyzes the conversion of tyrosine to dihydroxyphenylalanine. This is the first and rate-limiting step in the biosynthesis of catecholamines such as dopamine, epinephrine, and norepinephrine (Levitt et al., 1965). Antibodies to TH are used commonly to demonstrate catecholaminergic neurons and fibers (Hokfelt et al. 1984). Whether the TH-i cells detected in the striatum of normal monkeys (Dubach et al., 1987) and normal and dopamine-denervated rats (Tashiro et al., 1989) are dopaminergic is not known, however. Other TH-i cells, identified in intraocular grafts of fetal striatal tissue (Mahalik et al., 1989), organotypic slice cultures of neonatal striatum (Ostergaard et al., 1991), and dissociated cell cultures of fetal striatum (Du and Iacovitti, 1995; Du et al., 1995), also remain undefined. However, 

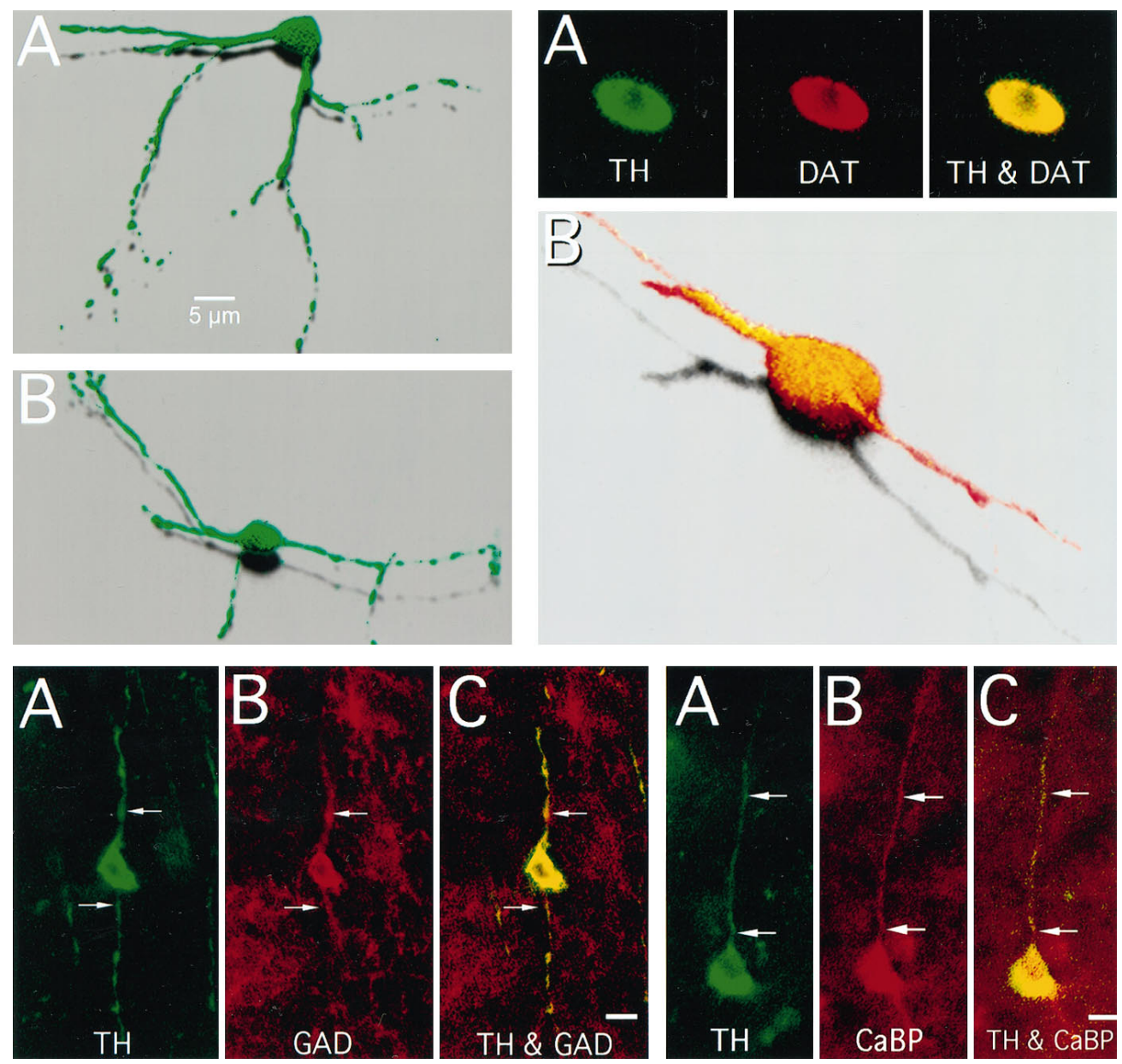

Figure 5. Top left. Examples of striatal aspiny TH-immunoreactive cells with varicose dendritic processes in MPTP-treated monkeys. The images are three-dimensional reconstructions of optical sections through TH-i cells that were obtained by confocal microscopy in $50 \mu \mathrm{m}$ sections of monkey brain.

Figure 6. Top right. TH-i cells of the MPTP-treated primate striatum also contain the dopamine transporter. $A$, Confocal images of an optical section through a TH-i cell that is also immunoreactive for DAT. TH immunoreactivity is green; DAT immunoreactivity is red; and areas of colocalization are yellow. $B$, Three-dimensional reconstruction of the cell in $A$ showing TH and DAT colocalization ( yellow).

Figure 7. Bottom left. Colocalization of TH and GAD in the striatal cells. Conventional fluorescent photomicrographs of a neuron (arrows) in the striatum of an MPTP-treated monkey that is both TH- and GAD-immunoreactive. Green fluorescence indicates TH immunoreactivity $(A)$; red fluorescence indicates GAD immunoreactivity $(B)$; and yellow fluorescence indicates colocalization $(C)$. GAD was found in $>99 \%$ of the TH-i cells. Scale bar, $10 \mu \mathrm{m}$

Figure 8. Bottom right. Colocalization of $\mathrm{TH}$ and calbindin in the striatal cells. Conventional fluorescent photomicrographs of a neuron and its process (arrows) in the striatum of an MPTP-treated monkey immunoreactive for both TH and CaBP. TH immunoreactivity is green $(A)$; $\mathrm{CaBP}$ is red $(B)$; and yellow fluorescence denotes colocalization $(C)$. Less than $1 \%$ of the TH-i cells in the striatum colocalized calbindin. Scale bar, $10 \mu \mathrm{m}$.

in the absence of immunoreactivity to dopamine- $\beta$-hydroxylase, dopa-decarboxylase and phenylethanolamine- $N$-methyltransferase, it was assumed that the TH-i cells were dopaminergic (Ostergaard et al. 1991). In this study, we established that striatal TH-i cells in adult monkeys were dopaminergic because they were also immunoreactive for DAT. Because DAT is a plasma membrane protein that is involved in the specific reuptake of dopamine, antibodies to DAT can be used as selective markers for dopaminergic neurons (Ciliax et al., 1995; Miller et al., 1997). Aside from establishing the dopaminergic nature of the $\mathrm{TH}-\mathrm{i}$ neurons, DAT co-localization indicates that these neurons contain an essential part of the machinery needed by functioning dopaminergic neurons.

Except for a few spiny cells, the TH-i cells in the striatum of adult monkeys were predominantly $(>99 \%)$ aspiny, bipolar neurons, similar to the cells described previously in intact striatum
(Dubach et al., 1987; Tashiro et al., 1989), intraocular striatal grafts (Mahalik et al., 1989), and striatal slice cultures (Ostergaard et al., 1991). Based on previous morphological descriptions of striatal neurons (DiFiglia et al., 1976; Bishop et al., 1982; Bolam et al. 1983), the aspiny TH-i cells we and others have seen (Iacovitti, 1991; Ostergaard et al., 1991; Du et al., 1995) best correspond to GABAergic, aspiny neurons. Our double-label studies with antibodies to TH and GAD provide the first indication that TH-i cells in the primate striatum are also GABAergic. Dopamine differentiation factor-treated striatal neurons in culture expressing $\mathrm{TH}$ have been shown to co-express $\mathrm{GAD}_{67}(\mathrm{Max}$ et al., 1996). Aspiny GABAergic neurons have been characterized as local circuit neurons by Bolam et al. (1983), and striatal cells intensely stained for GAD67 have been demonstrated to be interneurons (Augood et al., 1995). In the present study, striatal 

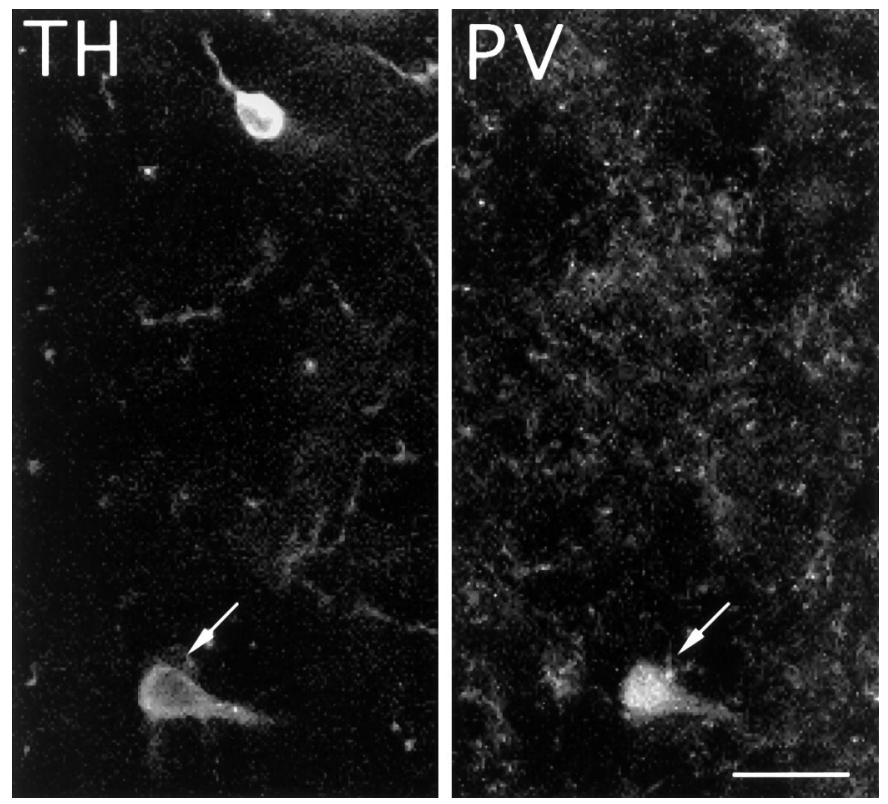

Figure 9. Colocalization of TH and parvalbumin in striatal cells. Fluorescent photomicrograph of a TH-immunnoreactive cell (arrow) in the striatum of an MPTP-treated monkey, which is also immuoreactive for $\mathrm{PV}$. Less than $1 \%$ of the striatal TH-i cells double-stained for parvalbumin. Scale bar, $20 \mu \mathrm{m}$.

interneurons, although retaining their GABAergic phenotype, were also apparently induced by dopamine depletion to coexpress $\mathrm{TH}$ and DAT. It might be hypothesized that these GABAergic interneurons begin to produce dopamine in partial compensation for the decreased levels of dopamine in the striatum after MPTP.

Co-expression of TH and GABAergic phenotypes has been reported in adult cerebral cortex (Kosaka et al., 1987), retina (Wulle and Wagner, 1990), hypothalamus (Everitt et al., 1984), and olfactory bulb (Gall et al., 1987). In olfactory bulb, both GABA and dopamine have been demonstrated to be inhibitory to the mitral cells (Shepherd, 1971; Getchell and Shepherd, 1975; Nowycky et al., 1983). However, because of the distinct mechanisms and durations of action of GABA and dopamine (Alger and Nicoll, 1982; Benardo and Prince, 1982), one or the other neurotransmitter likely has predominant postsynaptic influence. Although the physiological relevance of co-expression of dopaminergic and GABAergic traits in the striatal cells is not known, it is possible that both neurotransmitters have physiological postsynaptic effects. Moreover, the presence of DAT on the TH-i neurons confers on them the ability to take up and buffer endogenous or exogenous dopamine.

\section{Increase in TH-i cells in the striatum of MPTP-lesioned monkeys}

In our studies with monkeys, nigrostriatal degeneration caused a 3.5-fold increase in striatal TH-i cells. Tashiro et al., (1989) reported a similar response in rats, although we were unable to reproduce their results. The increase $\mathrm{TH}-\mathrm{i}$ striatal cells may be a response to the absence of appropriate dopaminergic inputs to striatum. It has long been considered that catecholamine transmitters are feedback inhibitors of TH (Spector et al., 1967; Zigmond et al., 1989), and it is possible that there exits a feedback mechanism whereby dopamine innervation regulates $\mathrm{TH}$ expression by striatal cells (Ostergaard et al., 1991). On the other hand, this would not fully explain the bilateral increase in TH-i striatal neurons seen after unilateral dopamine depletion in monkeys; other factors must also be involved. Expression of TH in striatal cells, triggered by loss of dopaminergic input, does not seem to be a transient phenomenon, because we found increased cells 2 months-2 years after MPTP treatment. The effects of dopaminergic therapy on these cells remains to be explored.

TH-i cells have been identified previously in the striatum of MPTP-treated monkeys, but it was reported that TH-i cell counts did not differ from those in control monkeys (Sladek et al., 1988). More recently, these investigators observed an increase in $\mathrm{TH}-\mathrm{i}$ cell density in the striatum of one marginally affected, MPTPtreated monkey (Elsworth et al., 1996). It was not stated however, whether $\mathrm{TH}-\mathrm{i}$ cells were seen or increased in the other, more severely affected monkeys. All the monkeys in our study were affected moderately to severely by MPTP. It would be of interest to examine expression of $\mathrm{TH}-\mathrm{i}$ in the striata of animals with various degrees of neurochemical and behavioral evidence of dopamine depletion.

A subgroup of cultured striatal neurons has the inherent ability to express TH (Du et al., 1995). A few scattered TH-positive cells were observed in dissociated striatal cell cultures; however, when exposed to acidic fibroblast growth factor and a catecholamine, a $60 \%$ increase in $\mathrm{TH}-\mathrm{i}$ cell density was observed. This suggests that de novo expression of the normally quiescent $\mathrm{TH}$ gene in noncatecholaminergic striatal neurons may be triggered under appropriate conditions (Iacovitti, 1991; Du and Iacovitti, 1995; Du et al., 1995). Glial cells, which are markedly increased after MPTP treatment (Francis et al., 1995), release growth factors (McMillian et al., 1994; Schwartz and Nishiyama, 1994). Also, striatal release of glutamate is enhanced after dopamine depletion (Calabresi et al., 1993; Yamamoto and Cooperman, 1994), and activation of glutamate receptors on cultured astrocytes can induce expression of NGF and bFGF mRNAs (Pechan et al., 1993). Thus, after dopamine denervation induced by MPTP, there may be a direct or indirect increase in astrocyte-specific expression of growth factors that, in turn, promotes increased striatal TH-i cell density. Future studies might address this possibility by examining TH expression in striatal cells after infusion of growth factors in normal and MPTP-treated monkeys.

Whether the increase in TH-i cells in the striatum of MPTPtreated monkeys represents cells with enhanced $\mathrm{TH}$ expression, which was previously undetectable immunocytochemically, acquisition of an additional phenotype by pre-existing GABAergic neurons, or "birth" of new neurons is unknown. Growth factors promote proliferation and differentiation of striatal ventricular zone cells in adult murine (Morshead et al., 1994), rat (Kirschenbaum and Goldman, 1995; Palmer et al., 1995), and human (Kirschenbaum et al., 1994) forebrain. It is conceivable that MPTP treatment triggers proliferation of these cells. The absence of lipof uscin in TH-i striatal cells, when it was present in most of the other striatal cells in the monkey, supports this possibility. Alternatively, it is possible that $\mathrm{TH}$ gene expression is triggered or enhanced in pre-existing striatal cells. It may be informative to examine the role of the Nurr1 receptor (Zetterstrom et al., 1997) and other regulatory components of cell fate specification, such as the sonic hedgehog signaling system (Hynes et al., 1995), that may determine dopaminergic fate of the striatal cells.

\section{Significance}

Traditionally, it has been believed that development of the mammalian brain involves a unique structural evolution that is accom- 
panied in its final steps by permanent loss of regenerative capacity (Altman, 1962; Kaplan 1988; Noble et al., 1990). However, recent studies suggest that certain brain regions retain some stem cells or pluripotential neurons, possibly to help compensate for natural attrition, disease, or injury. Adult striatal dopaminergic cells are such a population in that they responded to dopamine denervation by increasing in number. This is of tremendous potential interest, particularly if they can be recruited to manufacture and release dopamine within the striatum in Parkinson's disease. In this regard, studies to explore ways to manipulate $\mathrm{TH}$ expression in adult striatal cells will be of utmost importance.

\section{REFERENCES}

Alger BE, Nicoll RA (1982) Pharmacological evidence for two kinds of GABA receptor on rat hippocampal pyramidal cells studied in vitro. J Physiol (Lond) 328:125-141.

Altman J (1962) Are neurons formed in the brains of adult mammals? Science 135:1127-1128.

Augood SJ, Herbison AE, Emson PC (1995) Localization of GAT-1 GAB transporter mRNA in rat striatum: cellular coexpression with GAD67 mRNA, GAD67 immunoreactivity, and parvalbumin mRNA. J Neurosci 15:865-874.

Benardo LS, Prince DA (1982) Dopamine action on hippocampal cells. J Neurosci 2:415-423.

Bishop GA, Chang HT, Kitai ST (1982) Morphological and physiological properties of neostriatal neurons: an intracellular horseradish peroxidase study in the rat. Neuroscience 7:179-191.

Bolam JP, Clarke DJ, Smith AD, Somogyi P (1983) A type of aspiny neuron in the rat neostriatum accumulates ${ }^{3} \mathrm{H}$-gamma-aminobutyric acid: combination of Golgi-staining, autoradiography and electron microscopy. J Comp Neurol 213:121-134.

Bolam JP, Wainer BH, Smith AD (1984) Characterization of cholinergic neurons in the rat neostriatum. A combination of choline acetyltransferase immunocytochemistry, Golgi-impregnation and electron miocroscopy. Neuroscience 12:711-718.

Burns RS, Chiueh CC, Markey SP, Ebert MH, Jacobowitz DM, Kopin IJ (1983) A primate model of parkinsonism: selective destruction of dopaminergic neurons in the pars compacta of the substantia nigra by $N$-methyl-4-phenyl-1,2,3,6-tetrahydropyridine. Proc Natl Acad Sci USA 80:4546-4550.

Calabresi P, Mercuri NB, Sancessario G, Bernardi G (1993) Electrophysiology of dopamine-denervated striatal neurons. Implications for Parkinson's disease. Brain 116:433-452.

Ciliax BJ, Heilman C, Demchyshyn LL, Pristupa ZB, Ince E, Hersch SM, Niznik HB, Levey AI (1995) The dopamine transporter: immunochemical characterization and localization in brain. $\mathrm{J}$ Neurosci 15:1714-1723.

Cowan RL, Wilson CJ, Emson PC, Heizmann CW (1990) Parvalbumin containing GABAergic interneurons in the rat neostriatum. J Comp Neurol 302:197-205.

Dawson TM, Bredt DS, Fotuhi M, Hwang PM, Snyder SH (1991) Nitric oxide synthase and neuronal NADPH diaphorase are identical in the brain and peripheral tissues. Proc Natl Acad Sci USA 88:7797-7801.

DiFiglia M, Pasik P, Pasik T (1976) A Golgi study of neuronal types in the neostriatum of monkeys. Brain Res 114:245-256.

Du X, Iacovitti L (1995) Synergy between growth factors and transmitters required for catecholamine differentiation in brain neurons. J Neurosci 15:5420-5427.

Du X, Stull ND, Iacovitti L (1995) Brain-derived neurotrophic factor works coordinately with partner molecules to initiate tyrosine hydroxylase expression in striatal neurons. Brain Res 680:229-233.

Dubach M, Schmidt R, Kunkel D, Bowden DM, Martin R, German DC (1987) Primate neostriatal neurons containing tyrosine hydroxylase: immunohistochemical evidence. Neurosci Lett 75:205-210.

Ehringer H, Hornykiewicz O (1960) Verteilung von noradrenalin und dopamin (3-hydroxy-tyramin) im gehirn des menschen und ihr verhalten bei erkrankungen des extrapyramidalen systems. Klinische Wochenschrift 1236-1239.

Elsworth JD, Brittan MS, Taylor JR, Sladek Jr JR, Al-Tikriti MS, ZeaPonce Y, Innis RB, Redmond Jr DE, Roth RH (1996) Restoration of dopamine transporter density in the striatum of fetal ventral mesencephalon-grafted, but not sham-grafted, MPTP-treated Parkinsonian monkeys. Cell Transplant 5:315-325.
Everitt BJ, Hokfelt T, Wu JY, Goldstein M (1984) Coexistence of tyrosine hydroxylase-like and gamma-aminobutyric acid-like immunoreactivities in neurons of the arcuate nucleus. Neuroendocrinology 39:189-191.

Francis JW, Visger JV, Markelonis J, Oh TH (1995) Neuroglial responses to the dopaminergic neurotoxicant 1-methyl-4-phenyl-1,2,3,6tetrahydropyridine in mouse striatum. Neurotoxicol Teratol 17:7-12.

Gall CM, Hendry SHC, Seroogy KB, Jones EG, Haycock JW (1987) Evidence for coexistence of GABA and dopamine in neurons of the rat olfactory bulb. J Comp Neurol 266:307-318.

Gerfen CR, Wilson CJ (1996) The basal ganglia. In: Handbook of chemical neuroanatomy (Swanson LW, Bjorklund A, Hokfelt T, eds), pp 371-468. Amsterdam: Elsevier.

Gerfen CR, Baimbridge KG, Miller JJ (1985) The neostriatal mosaic: compartmental distribution of calcium-binding protein and parvalbumin in the basal ganglia of the rat and monkey. Proc Natl Acad Sci USA 82:8780-8784.

Getchell TV, Shepherd GM (1975) Short-axon cells in the olfactory bulb: dendrodendritic synaptic interaction. J Physiol (Lond) 251:523-548.

Heikkila RE, Hess A, Duvosin RC (1984) Dopaminergic neurotoxicity of 1-methyl-4-phenyl-1,2,3,6-tetrahydropyridine in mice. Science 224:1451-1453.

Hokfelt T, Johansson O, Goldstein M (1984) Central catecholamine neurons as revealed by immunohistochemistry with special reference to adrenaline neurons. In: Handbook of chemical neuroanatomy (Bjorklund A, Hokfelt T, eds), pp 170-186. Amsterdam: Elsevier.

Hynes M, Poulsen K, Tessier-Lavigne M, Rosenthal A (1995) Control of neuronal diversity by the floor plate: contact-mediated induction of midbrain dopaminergic neurons. Neuron 80:95-101.

Iacovitti L (1991) Effects of a novel differentiation factor on the deveopment of catecholamine traits in noncatecholamine neurons from various regions of the rat brain: studies in tissue culture. J Neurosci 11:2403-2409.

Kaplan MS (1988) Plasticity after brain lesions: contemporary concepts. Arch Phys Med Rehabil 69:984-991.

Kemp JM, Powell TPS (1971) The structure of the caudate nucleus of the cat: light and electron microscopic analysis with the PHA-L method. J Comp Neurol 260:435-452.

Kirschenbaum B, Goldman SA (1995) Brain-derived neurotrophic factor promotes the survival of neurons arising from the adult rat forebrain subependymal zone. Proc Natl Acad Sci USA 92:210-214.

Kirschenbaum B, Nedergaard M, Preuss A, Barami K, Fraser RAR, Goldman SA (1994) In vitro neuronal production and differentiation by precursor cells derived from the adult human brain. Cereb Cortex 6:576-589.

Kita H (1993) GABAergic circuits of the striatum. Prog Brain Res 99:51-72.

Kita H, Kitai ST (1988) Glutamate decarboxylase immunoreactive neurons in rat striatum: their morphological types and populations. Brain Res 29:229-322.

Kita H, Kosaka T, Heizmann CW (1990) Parvalbumin-immunoreactive neurons in the rat neostriatum:a light and electron microscopic study. Brain Res 536:1-15.

Kosaka T, Kosaka K, Hataguchi Y, Nagatsu I, Wu JY, Ottersen OP, Storm-Mathisen J, Hama K (1987) Catecholamine neurons containing GABA-like and/or glutamic acid decarboxylase-like immunmoreactivities in various brain regions of the rat. Exp Brain Res 66:191-210.

Langston JW, Ballard PA, Tetrud JW, Irwin I (1983) Chronic parkinsonism in humans due to a product of meperidine analog synthesis. Science 219:979-980.

Levitt M, Spector S, Sjoerdsma A, Udenfriend S (1965) Elucidation of rate-limiting step of norepinephrine biosynthesis in the perfused guinea pig heart. J Pharmacol Exp Ther 148:1-8.

Mahalik TJ, Stromberg I, Finger TE, Olson L (1989) Abnormal expression of tyrosine hydroxylase-like immunoreactivity in intraocular transplants of rat caudate nucleus. Neurosci Lett 96:253-258.

Max SR, Bossio A, Iacovitti L (1996) Co-expression of tyrosine hydroxylase and glutamic acid decarboxylase in dopamine differentiation factor-treated striatal neurons in culture. Dev Brain Res 91:140-142.

McMillian MK, Thai L, Hong JS, O'Callaghan JP, Pennypacker KR (1994) Brain injury in a dish: a model for reactive gliosis. Trends Neurosci 17:138-142.

Miller GW, Staley JK, Heilman CJ, Perez JT, Mash DC, Rye DB, Levey AI (1997) Immunocytochemical analysis of dopamine transporter protein in Parkinson's disease. Ann Neurol 41:530-539. 
Morshead CM, Reynolds BA, Craig C, McBurney MW, Staines WA, Morassutti D, Weiss S, van der Kooy D (1994) Neural stem cells in the adult mammalian forebrain: a relatively quiescent subpopulation of subependymal cells. Neuron 13:1071-1082.

Noble M, Fok-Seang J, Wolswijk G, Wren D (1990) Development and regeneration in the central nervous system. Philos Trans R Soc Lond [Biol] 327:127-143.

Nowycky MC, Halasz N, Shepherd GM (1983) Evoked field potential analysis of dopaminergic mechanisms in the isolated turtle olfactory bulb. Neuroscience 8:717-722.

Oertel WH, Mugnaini E (1984) Immunocytochemical studies of GABAergic neurons in the rat basal ganglia and their relations to other neural systems. Neurosci Lett 47:233-238.

Ostergaard K, Schou JP, Gahwiler BH, Zimmer J (1991) Tyrosine hydroxylase immunoreactive neurons in organotypic slice cultures of the rat striatum and neocortex. Exp Brain Res 83:357-365.

Palmer TD, Ray J, Gage FH (1995) FGF-2-responsive neuronal progenitors reside in proliferative and quiescent regions of the adult rodent brain. Mol Cell Neurosci 6:474-486.

Parent A, Cote P, Lavoie B (1995) Chemical anatomy of primate basal ganglia. Prog Neurobiol 46:131-197.

Pasik P, Pasik T, Holstein GR, Hamori J (1988) GABAergic elements in the neuronal circuits of the monkey neostriatum: a light and electron microscopic immunocytochemical study. J Comp Neurol 270:157-170.

Pechan PA, Chowdhury K, Gerdes W, Seifert W (1993) Glutamate induces the growth factors NGF, bFGF, the receptor FGF-R1 and c-fos mRNA expression in rat astrocyte culture. Neurosci Lett 153:111-114.

Schwartz JP, Nishiyama N (1994) Neurotrophic factor gene expression in astrocytes during development and following injury. Brain Res Bull 35:403-407.

Shepherd GM (1971) Physiological evidence for dendrodendritic synaptic interaction in the rabbit's olfactory glomerulus. Brain Res 32:212-217.

Sladek Jr JR, Redmond Jr DE, Collier TJ, Blount JP, Elsworth JD, Taylor JR, Roth RH (1988) Fetal dopamine neural grafts: extended reversal of methylphenyltetrahydropyridine-induced parkinsonism in monkeys. Prog Brain Res 78:497-506.

Smith Y, Parent A (1986) Neuropeptide Y-immunoreactive neurons in the striatum of the cat and monkey: morphological characteristics, intrinsic organization and co-localization with somatostatin. Brain Res 372:241-252.

Smith Y, Parent A, Seguela P, Descarries L (1987) Distribution of GABA-immunoreactive neurons in the basal ganglia of the squirrel monkey (Samiri sciureus). J Comp Neurol 259:50-61.

Spector S, Gordon R, Sjoerdsma A, Udenfriend S (1967) End-product inhibition of tyrosine hydroxylase as a possible mechanism for regulation of norepineprine synthesis. Mol Pharmacol 3:549-555.

Tashiro Y, Sugimoto T, Hattori T, Uemura Y, Nagatsu I, Kikuchi H, Mizuno N (1989) Tyrosine hydroxylase-like immunoreactive neurons in the striatum of the rat. Neurosci Lett 97:6-10.

Ungerstedt U (1968) 6-Hydroxydopamine induced degeneration of central monoamine neurons. Eur J Pharmacol 5:107-110.

Ungerstedt U (1971) Histochemical effects of intracerebral and intraventricular injections of 6-hydroxydopamine on monoamine neurons in the rat brain. In: 6-Hydroxydopamine and catecholamine neurons (Malmfors T, Thoenen H, eds), pp 101-127. Amsterdam: NorthHolland.

Vincent SR, Johansson O, Hokfelt T, Skirboll L, Elde RP, Teremus L, Kimmel J, Goldstein M (1983a) NADPH-diaphorase: a selective histochemical marker for striatal neurons containing both somatostatinand avian pancreatic polypeptide (APP-) like immunoreactivity J Comp Neurol 217:252-263.

Vincent SR, Staines WA, Fibiger HC (1983b) Histochemical demonstration of separate populations of somatostatin and cholinergic neurons in the rat striatum. Neurosci Lett 35:111-114.

Wulle I, Wagner HJ (1990) GABA and tyrosine hydroxylase immunocytochemistry reveal different patterns of colocalization in retinal neurons of various vertebrates. J Comp Neurol 296:173-178.

Yamamoto BK, Cooperman MA (1994) Differential effects of antipsychotic treatment on extracellular glutamate and dopamine concentrations. J Neurosci 14:4159-4166.

Zetterstrom RH, Solomin L, Jansson L, Hoffer BJ, Olson L, Pearlmann T (1997) Dopamine neuron agenesis in Nurr1-deficient mice. Science 276:248-250.

Zigmond RE, Schwarzschild MA, Rittenhouse AR (1989) Acute regulation of tyrosine hydroxylase by nerve activity, by neurotransmitters and by phosphorylation. Annu Rev Neurosci 12:415-461. 